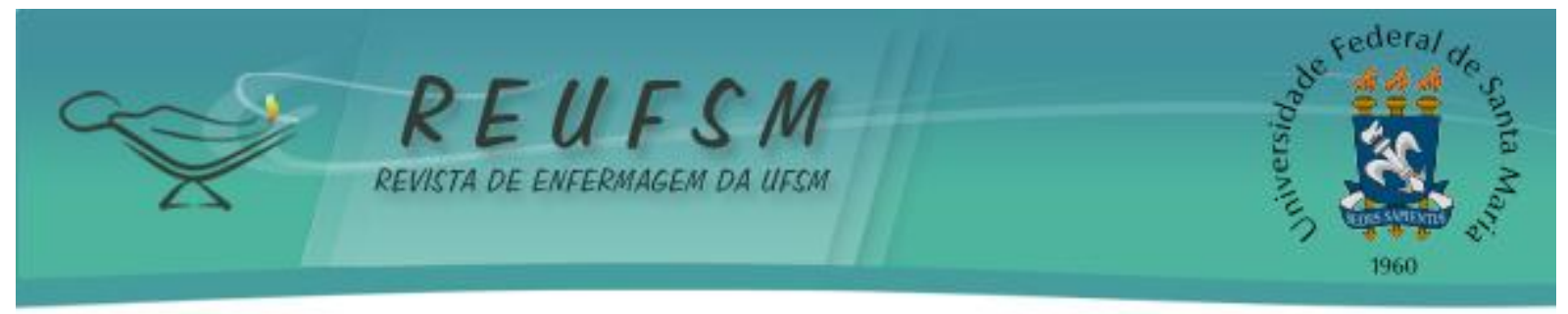

RELATO DE EXPERIENCIA

\title{
MONITORIA EM SEMIOLOGIA E SEMIOTÉCNICA PARA A ENFERMAGEM: UM RELATO DE EXPERIÊNCIA
}

\author{
MONITORING IN SEMIOLOGY AND SEMIO-TECHNIQUES FOR NURSING: AN EXPERIENCE \\ STORY
}

\section{MONITORIA EN SEMIOLOGIA Y SEMIOTÉCNICA PARA LA ENFERMERÍA: UN RELATO DE LA EXPERIENCIA}

\author{
Isaiane da Silva Carvalho ${ }^{1}$ \\ Alcides Viana de Lima Neto ${ }^{2}$ \\ Francisco das Chagas Freitas Segundo ${ }^{3}$ \\ Gysella Rose Prado de Carvalho ${ }^{4}$ \\ Vilani Medeiros de Araújo Nunes ${ }^{5}$
}

RESUMO: Objetivo: relatar a experiência de acadêmicos de enfermagem no desempenho de suas atividades de monitoria na disciplina semiologia e semiotécnica para enfermagem em uma instituição de ensino superior da cidade de Natal, Rio Grande do Norte, no período compreendido entre os meses de setembro de 2009 a setembro de 2010. Método: as atividades foram realizadas no laboratório de enfermagem e efetuaram-se de duas formas: na primeira, ocorria o acompanhamento pelos monitores, juntamente com os professores das aulas práticas da disciplina e, na segunda, os monitores realizavam as atividades de orientação aos alunos que estavam cursando a disciplina. Resultados: a Monitoria possibilita uma experiência diferenciada ao aluno que por ela opta, visto as inúmeras experiências que podem ser vivenciadas em seu âmbito. Conclusões: por meio dessa atividade, os monitores desenvolveram ações de ensino, pesquisa e extensão que possibilitaram a consolidação de conhecimentos.

Descritores: Enfermagem; Ensino; Aprendizagem; Educação em enfermagem; Estudantes de enfermagem.

ABSTRACT: Objective: to report the experience of nursing students on performance of their monitoring activities in the discipline semiotics and semiology to nursing at an institution of higher education in Natal, Rio Grande do Norte, in the period between the months of September 2009 to September 2010. Method: the activities were performed in the nursing laboratory and carried out in two ways: first, there was monitoring the monitors, along with teachers of the practical lessons of discipline and, second, the monitors performed the orientation activities for students who were attending the course. Results: monitoring provides a differentiated experience to the student who opts for it, given the many experiences that can be experienced in its scope. Conclusions: through this activity, monitors actions developed teaching, research and extension that allowed the consolidation of knowledge.

Descriptors: Nursing; Teaching; Learning; Education in nursing; Nursing students.

\footnotetext{
${ }^{1}$ Enfermeira. Bacharel em Enfermagem pela Faculdade de Excelência Educacional do Rio Grande do Norte/FATERN. E-mail: isaianekarvalho@hotmail.com

${ }^{2}$ Enfermeiro. Bacharel em Enfermagem pela Faculdade de Excelência Educacional do Rio Grande do Norte/FATERN. E-mail: alcides.vln@bol.com.br

${ }^{3}$ Enfermeiro. Bacharel em Enfermagem pela Faculdade de Excelência Educacional do Rio Grande do Norte/FATERN. E-mail: enfsegundo@hotmail.com

${ }^{4}$ Enfermeira. Mestre em Enfermagem pelo Programa de Pós-Graduação em Enfermagem da Universidade Federal do Rio Grande do Norte/UFRN. E-mail: gysellacarvalho@terra.com.br

${ }^{5}$ Professora Assistente da Universidade Federal do Rio Grande do Norte/UFRN. Mestre em Enfermagem; Doutoranda em Ciências da Saúde/UFRN. E-mail: vilani.nunes@gmail.com
} 


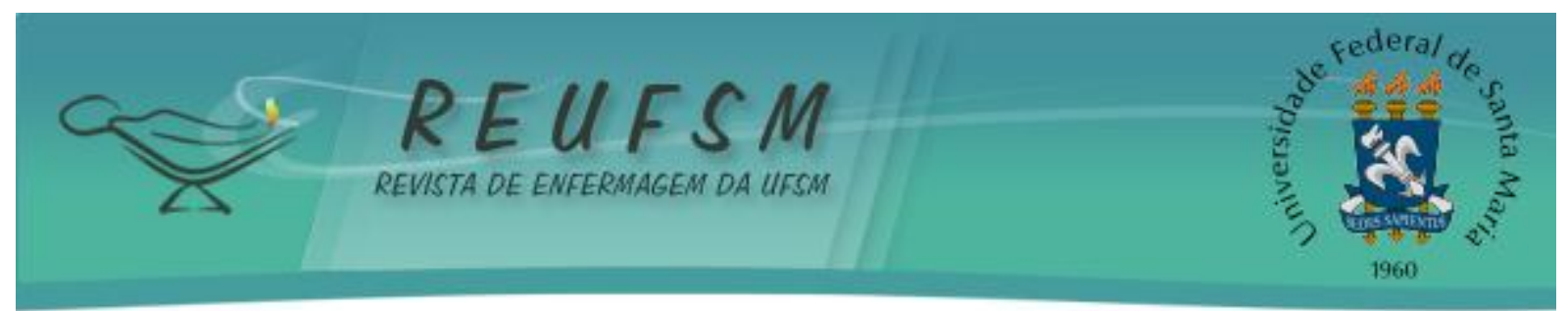

RESUMEN: Objetivo: presentar la experiencia de los estudiantes de enfermería en la realización de sus actividades de monitoria en la disciplina Semiología y Semiotécnica para la enfermería en una institución de educación superior en Natal, Rio Grande do Norte, en el período comprendido entre los meses de septiembre de 2009 hasta septiembre de 2010. Método: las actividades se realizaron en el laboratorio de enfermería y llevado a cabo de dos maneras: en la primera, ocurría el acompañamiento por los monitores, junto con los maestros de las lecciones prácticas de la disciplina y, la segunda, los monitores realizan las actividades de orientación para los estudiantes que se encontraban asistir al curso. Resultados: la vigilancia proporciona una experiencia diferenciada al estudiante que opta por ella, como también las muchas experiencias que se pueden experimentar en su ámbito de aplicación. Conclusiones: a través de esta actividad, los monitores desarrollaron acciones de enseñanza, investigación y extensión que permite la consolidación del conocimiento.

Descriptores: Enfermería; Enseñanza; Aprendizaje; Educación en enfermería; Estudiantes de enfermería.

\section{INTRODUÇÃO}

A enfermagem envolve uma série de conhecimentos técnicos e científicos, desenvolvidos por meio de práticas sociais, éticas e políticas que ocorrem através do ensino, pesquisa e extensão, efetuando-se sob a prestação de serviços ao indivíduo, família e comunidade em consonância com o contexto no qual se encontram inseridos. ${ }^{1}$

0 curso de Bacharelado em Enfermagem de uma Instituição de Ensino Superior IES, localizada no estado do Rio Grande do Norte - RN, foi autorizado pela portaria $n^{\circ} 262$ de 2007 da Secretaria de Educação Superior de março de 2007 e encontra-se em processo de reconhecimento pelo Ministério da Educação. ${ }^{2}$ A primeira matriz curricular implantada possui uma carga horária total de 3.860 horas, das quais, 220 horas destinam-se às disciplinas de Semiologia e Semiotécnica I e II.

A inserção da disciplina de Semiologia e Semiotécnica nos cursos de enfermagem tornou-se obrigatória com a reestruturação curricular ocorrida no ano de 1994, proposta por meio da portaria $\mathrm{n}^{\circ} 1721$ de 15 de dezembro de $1994^{3}$, a qual pode abordar conteúdos específicos ou integrar-se a outras disciplinas, de acordo com a necessidade e realidade de cada curso onde estiver inserida. ${ }^{4}$ Tal disciplina possibilita 0 desenvolvimento de habilidades na execução de procedimentos teórico-práticos, necessários a assistência de enfermagem, com foco ao indivíduo, família e comunidade, sendo de fundamental importância para o desenvolvimento das atividades de enfermagem. ${ }^{5}$

A monitoria compreende um serviço de apoio pedagógico que possibilita aos acadêmicos a oportunidade de aprofundar conhecimentos e solucionar eventuais dificuldades relacionadas à disciplina trabalhada. ${ }^{6}$ Nesse sentido, permite a ocorrência de uma melhor correlação entre teoria e prática, possibilitando que durante o processo de ensino e aprendizagem, seja criado um espaço onde o aluno possa interrogar, praticar e revisar conteúdos trabalhados em sala de aula com menor grau de receio, favorecendo assim, um maior nível de confiança quanto à realização dos procedimentos. ${ }^{7}$

A mesma encontra-se prevista na Lei $N^{\circ}$ 9.394, de 20 de Dezembro de 1996, a qual estabelece as diretrizes e bases da educação nacional. Em seu artigo 84, a referida lei dispõe que "os discentes da educação superior poderão ser aproveitados em tarefas de ensino e pesquisa pelas respectivas instituições, exercendo funções de monitoria, de acordo com seu rendimento e seu plano de estudos". 8:30

O programa institucional de monitoria objetiva incorporar o discente em atividades docentes, viabilizando a consolidação de sua formação acadêmica e a melhoria 


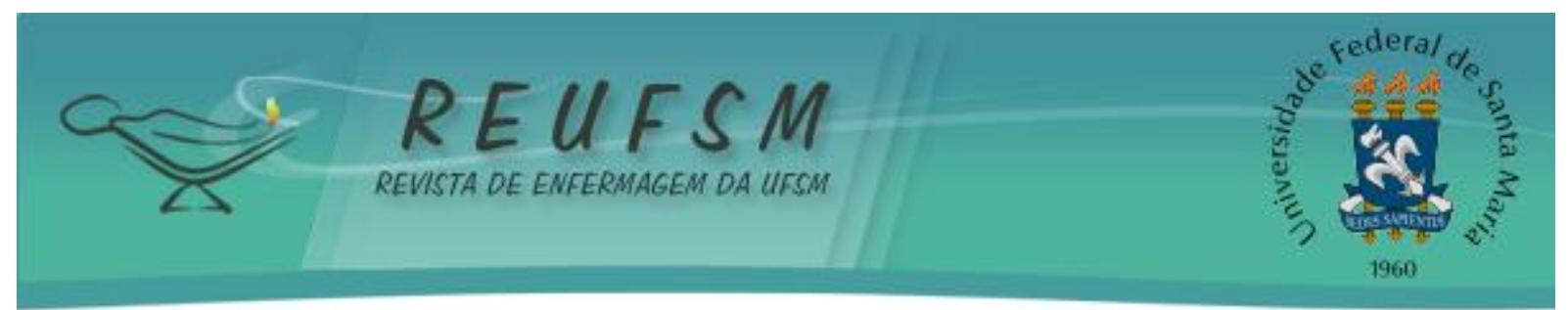

da qualidade do processo de aprendizagem. Além disso, fornece auxílio ao professor nas atividades didáticas desenvolvidas em sala de aula e laboratório. ${ }^{9}$

A monitoria, assim como outras atividades de ensino, proporciona 0 desenvolvimento de habilidades teórico-práticas através do suporte que é fornecido aos alunos assistidos. ${ }^{10} \mathrm{Em}$ se tratando do aluno-monitor, as atividades de monitoria constituem-se como uma experiência ímpar em sua carreira acadêmica, uma vez que contribuirá para a sua formação em termos de ensino, pesquisa e extensão. 0 desenvolvimento de tais atividades configura-se como uma prática comum no meio acadêmico, embora seja evidenciado um déficit de estudos que abordem a temática. ${ }^{11}$

O relato de uma experiência está além de uma mera descrição sumária sobre alguma atividade, haja vista que ao efetuar a sua leitura, é possível conhecer com mais propriedade a experiência descrita ainda que, do ponto de vista teórico, além de compará-la com outras experiências semelhantes, possibilitando a reflexão sobre o assunto. Desta forma, o referido relato de experiência justifica-se por possibilitar a ampliação de novas discussões sobre a temática e fornecer subsídios para o desenvolvimento de pesquisas.

Assim, tem-se como objetivo relatar a experiência de acadêmicos de enfermagem no desempenho de suas atividades de monitoria na disciplina semiologia e semiotécnica para enfermagem em uma IES, situada na cidade de Natal - RN, no período compreendido entre os meses de setembro de 2009 a setembro de 2010.

\section{MÉTODO}

Trata-se de um relato de experiência, forma metodológica que permite a descrição de experiências vivenciadas ${ }^{12}$, de natureza qualitativa, uma vez que evidencia aspectos subjetivos do ser humano. ${ }^{13}$

Esse relato foi realizado com base nas experiências dos monitores da disciplina de Semiologia e Semiotécnica para Enfermagem que desenvolveram suas atividades didáticopedagógicas em um dos laboratórios de práticas de enfermagem de uma IES, no período de setembro de 2009 a setembro de 2010.

Para tanto, efetuou-se uma análise crítica das atividades desenvolvidas como monitores da disciplina e dos relatórios individuais desenvolvidos ao final de cada semestre letivo. Tais relatórios objetivavam a descrição sucinta dos principais aspectos relacionados ao processo de ensino-aprendizagem vivenciados no período em que transcorreu a monitoria.

No âmbito da disciplina de Semiologia e Semiotécnica para Enfermagem, as atividades de monitoria foram desenvolvidas por alunos-monitores que previamente cursaram a referida disciplina. Além disso, os estudantes foram aprovados em processo seletivo instituído no segundo semestre de 2009, por intermédio de solicitação da diretoria acadêmica da IES em concordância com a coordenação do curso de enfermagem e a gerência dos laboratórios da saúde.

O mesmo constituiu-se de prova escrita, entrevista com a gerência dos laboratórios da saúde e com o setor de recursos humanos e análise do rendimento acadêmico dos candidatos. Na ocasião, foram selecionados seis monitores, posteriormente distribuídos nos turnos matutino (um monitor), vespertino (dois monitores) e noturno (três monitores), de acordo com a disponibilidade de cada um e as necessidades do laboratório. Destaca-se que as informações contidas no presente relato referem-se à experiência vivenciada pelos monitores do turno noturno (19h às $22 \mathrm{~h}$ ), período em que se deu o desenvolvimento de suas atividades como monitores da disciplina de Semiologia e Semiotécnica para Enfermagem.

Conforme o programa de monitoria da IES, ao monitor são atribuídas as funções de: 


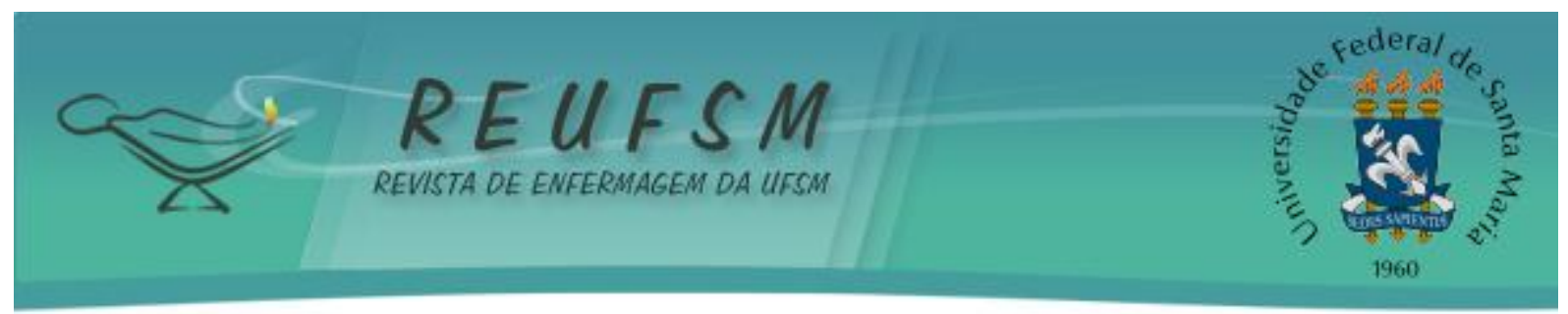

Atuar unicamente em atividades de ensino, em uma única disciplina (já cursada e com bom rendimento acadêmico); trabalhar sob orientação do professor da disciplina; e cumprir os horários estabelecidos, assinando o registro de presença na Central de Atendimento, sob a supervisão da Gerência de Laboratórios. ${ }^{9: 1}$

As atividades realizadas no laboratório efetuaram-se de duas formas: na primeira, ocorria o acompanhamento pelos monitores, juntamente com os professores, das aulas práticas da disciplina e na segunda, os monitores realizavam as atividades de orientação aos alunos que estavam cursando a disciplina e procuravam o laboratório, em horários diferentes aos das aulas, para exercitar e esclarecer as dúvidas acerca dos assuntos discutidos em sala de aula.

\section{RESULTADOS}

\section{Contextualizando o ensino-aprendizado}

A disciplina de Semiologia e Semiotécnica integra a matriz curricular obrigatória do curso de Bacharelado em Enfermagem, sendo desenvolvida nos $3^{\circ}$ e $4^{\circ}$ semestres, na grade curricular I, a qual os monitores envolvidos estão inseridos, sob a forma de Semiologia e Semiotécnica I e II, com carga-horária de 100 horas-aula (ha) e 120 ha, respectivamente.

A Semiologia e Semiotécnica I aborda conteúdos teóricos básicos como definições de semiologia, registros de enfermagem, medidas de conforto e higiene do paciente e do ambiente, biossegurança, lavagem das mãos e calçamento de luvas, medidas de controle e prevenção de infecção, comunicação terapêutica, os cinco sinais vitais e medidas antropométricas, anamnese e métodos propedêuticos, exame físico completo detalhando cada região do corpo humano, vias de administração de medicamentos, entre outros, tendo $60 \mathrm{~h} / \mathrm{a}$ destinadas a conteúdos ministrados em sala de aula e $40 \mathrm{~h} / \mathrm{a}$ para o desenvolvimento de práticas em laboratório. A Semiologia e Semiotécnica II, por sua vez, apresenta $50 \mathrm{~h} / \mathrm{a}$ para conteúdo teórico ministrado em sala de aula, que envolve a sistematização das assistências de enfermagem em situações mais complexas, como distúrbios de nutrição, de eliminações fisiológicas, soluções de continuidade, venóclise, dentre outras e $70 \mathrm{~h} / \mathrm{a}$ destinadas a atividades práticas $(40 \mathrm{~h} / \mathrm{a}$ em laboratório e $30 \mathrm{~h} / \mathrm{a}$ para ensino clínico em unidades de saúde).

Neste contexto, as aulas práticas no curso de graduação em enfermagem, sejam em laboratório ou em unidades de saúde, visam subsidiar a formação profissional através da construção diária de práticas que culminam com o enfrentamento de problemas e tomada de decisões que estimulam o desenvolvimento de um profissional críticoautônomo-reflexivo. ${ }^{14}$

As aulas da disciplina em questão seguem um cronograma estabelecido previamente, no qual constam todas as atividades que serão desenvolvidas ao longo do semestre, distribuídas pelas datas referentes aos dias da disciplina e os professores que irão ministrá-las. No período em que o laboratório não está ocupado com a realização de aulas práticas, esse é destinado para que os alunos esclareçam dúvidas sobre o assunto estudado, com o auxílio dos monitores.

A metodologia organizacional supracitada é semelhante à praticada por um curso de graduação em enfermagem de uma universidade pública de São Paulo. Nesta instituição, as aulas de laboratório são incluídas em cronogramas e os estudantes podem procurar 


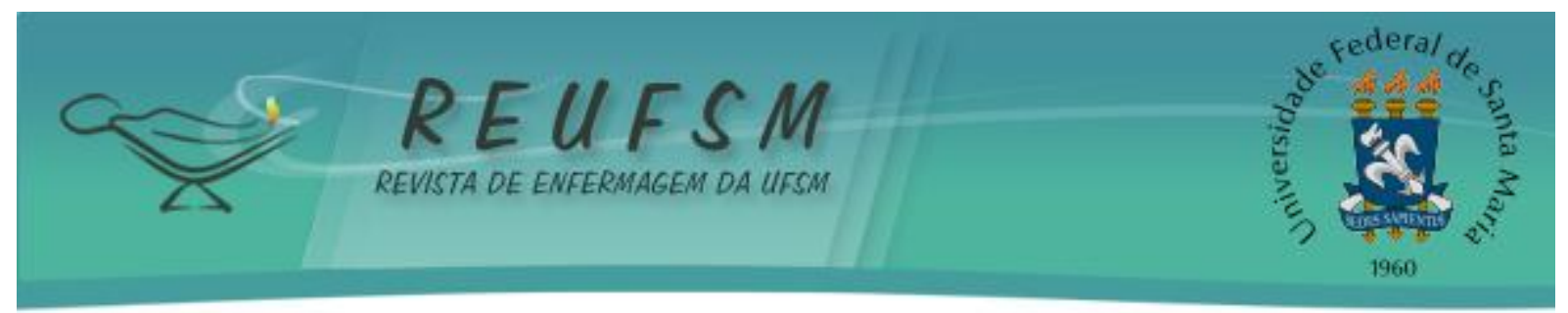

espontaneamente o laboratório para a prática de procedimentos relacionados às disciplinas de Fundamentação do Processo de Cuidar e Administração de Medicamentos, dentre outras. ${ }^{15}$

0 processo de ensino-aprendizagem deve adotar uma didática que não pode reduzir-se ou dedicar-se apenas ao ensino de meios e mecanismos tradicionais de ensino e sim, deverá apoiar-se em um modo crítico de desenvolver uma prática educativa que não é feita somente pelo educador, mas por ele, em associação com o educando e outros membros da sociedade. ${ }^{16}$

\section{Experiência vivenciada}

O laboratório de Enfermagem destina-se ao desenvolvimento de atividades de conteúdo prático referentes à disciplina de Semiologia e Semiotécnica para Enfermagem. A sua capacidade de funcionamento é de 25 alunos por aula, assim, as turmas que excedem este número são divididas em grupos, para que não ocorra prejuízo de aprendizagem devido à superlotação.

A formação de grupos é um método interessante de organização da prática pedagógica. Os grupos representam uma amostra da sociedade e é por meio deles que os alunos se preparam para viver coletivamente. A vivência das situações com o grupo desencadeia no educando um preparo para uma conduta social adequada, pois por meio da interação com os semelhantes estará se formando uma consciência democrática. ${ }^{16}$

A rotina do laboratório consiste no funcionamento pela manhã, tarde e noite, tanto para a realização de aulas práticas, quanto para atendimento aos alunos. Para a realização das aulas práticas, os professores fazem o agendamento e solicitam o material que será utilizado diretamente aos monitores, já os alunos, agendam o horário para esclarecer as dúvidas e realização de procedimentos nos manequins do laboratório, na Central de Atendimento ao Aluno. Em todos os horários, as atividades desenvolvidas no laboratório são supervisionadas pelos monitores, valendo destacar que os mesmos não têm autorização para dar aulas nem substituir professores.

0 ambiente do laboratório configura-se como um espaço propício ao aprendizado, uma vez que os alunos têm a oportunidade de simular a realização de procedimentos que farão parte de sua vida profissional e, consequentemente, desenvolver e aprimorar habilidades psicomotoras antes de um contato real com os pacientes. ${ }^{15}$

Entretanto, muito mais que um espaço destinado ao desenvolvimento de procedimentos, o laboratório de Enfermagem deve ser concebido como um momento fértil para explorar a reflexão, criação e compreensão, com vista a produção de um conhecimento norteado por ações que envolvem "o pensar, o fazer, o conviver e o ser". 17:407

O monitor deve cumprir 20 horas semanais, sendo cinco horas destinadas ao estudo da disciplina e 15 horas de atendimento presencial no laboratório, distribuídas ao longo da semana e com escala aos sábados pela manhã.

Percebe-se que, excetuando-se o horário de aulas em laboratório, há pouca procura por parte dos alunos para esclarecer dúvidas sobre o conteúdo ministrado, realidade alterada na semana que antecede as atividades avaliativas, principalmente as avaliações práticas.

Para que o aluno acompanhe as atividades desenvolvidas no laboratório é necessário que esse porte equipamentos básicos de proteção individual - EPI, que são o sapato fechado e o uso do jaleco. Tal norma, por vezes, ocasiona descontentamento nos mesmos que insistem em adentrar ao laboratório sem os itens mencionados e, consequentemente, são convidados a retirar-se do local.

No decorrer do processo de ensino-aprendizagem o aluno, ao desenvolver atividades práticas em instituições de saúde, expõe-se aos mesmos riscos que um 


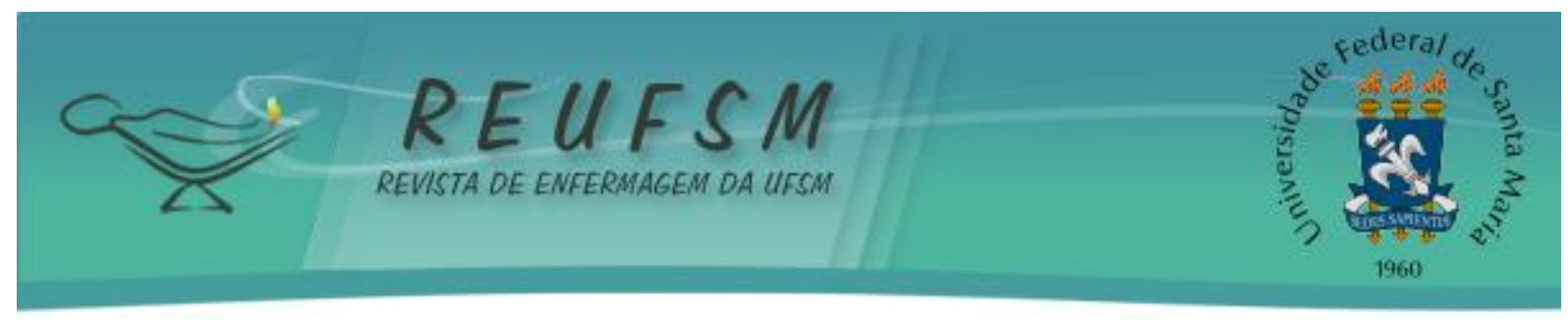

profissional de enfermagem. Assim, o estímulo à simulação de procedimentos, com foco na segurança do profissional através do uso de EPI, contribui para o desenvolvimento de uma assistência voltada a "promoção da saúde pessoal e dos clientes sob os seus cuidados". 18:264

A monitoria possibilita uma experiência diferenciada ao aluno que por ela opta, visto as inúmeras experiências que podem ser vivenciadas em seu âmbito, quais sejam: consolidação de conhecimentos teórico-práticos; segurança quanto à realização de procedimentos inerentes a disciplina e maior visibilidade acadêmica; aprofundamento de relações com discentes dos demais períodos do curso e com os professores da disciplina; e visão crítica acerca do processo de ensino e aprendizagem.

O monitor, ao estar em contato diariamente com as atividades desenvolvidas na monitoria, tem oportunidade maior de aprofundar os conteúdos da disciplina, quando comparado a outros alunos que apenas a cursaram no período correspondente, facilitando tanto o desempenho de atividades enquanto monitor, como também enquanto aluno, haja vista que o monitor também é um aluno.

Ressalta-se que a monitoria possibilita um espaço para o desenvolvimento de vínculos entre alunos, que veem o monitor como referência, alguém que pode thes orientar sobre alguns detalhes presentes no desenvolvimento de atividades práticas, uma vez que esse já vivenciou aquela situação em um momento anterior na condição de aluno. Além disso, a estreita relação com o docente permite o aprendizado de novos conhecimentos e maiores oportunidades no que concerne ao desenvolvimento de outras atividades, com especial destaque para a pesquisa e a extensão.

Contudo, as universidades têm ratificado a prática da monitoria como algo mais direcionado ao ensino, sendo necessário o estímulo a meios que busquem integrar também as atividades de pesquisa e extensão. Desde que auxiliado a apropriar-se dos conhecimentos necessários, o monitor poderá exercer atividades nesses três campos de atuação. ${ }^{19}$

O contato com diferentes metodologias de ensino e aprendizagem, desenvolvidas pelos docentes da disciplina, possibilita que o monitor desenvolva uma análise crítica acerca de tal processo, favorecendo a formulação de sua própria metodologia e que, certamente influenciará de forma significativa no perfil do docente que se desenvolverá, caso o monitor tenha interesse em trilhar esse caminho.

\section{CONCLUSÃO}

A monitoria configurou-se como uma importante atividade exercida pelo monitor para o seu crescimento pessoal e profissional. Através dessa experiência os monitores puderam desenvolver atividades de ensino, pesquisa e extensão que possibilitaram a consolidação de diversos conhecimentos.

Tais atividades representaram uma importante experiência de aprendizado para o monitor, dado a grande oportunidade de conhecer e vivenciar de forma mais intensa a dinâmica do processo de ensino-aprendizagem sob a luz da docência, caracterizada por um processo mútuo de troca de conhecimentos.

Contudo, alguns fatores dificultaram o desempenho das atividades de monitoria: a inadequação dos alunos quanto às normas de biossegurança e institucionais vigentes para frequentarem os laboratórios e a falta de determinados materiais que poderiam vir a enriquecer o processo de ensino e aprendizagem. Tais desafios puderam ser superados com um processo de organização prévia.

Considerando a relevância da produção científica para consolidar as bases teóricas e práticas de uma atividade, sugere-se a realização de pesquisas no intuito de suscitar discussões profundas sobre essa metodologia de ensino utilizada no âmbito de vários cursos, inclusive nos de enfermagem. 


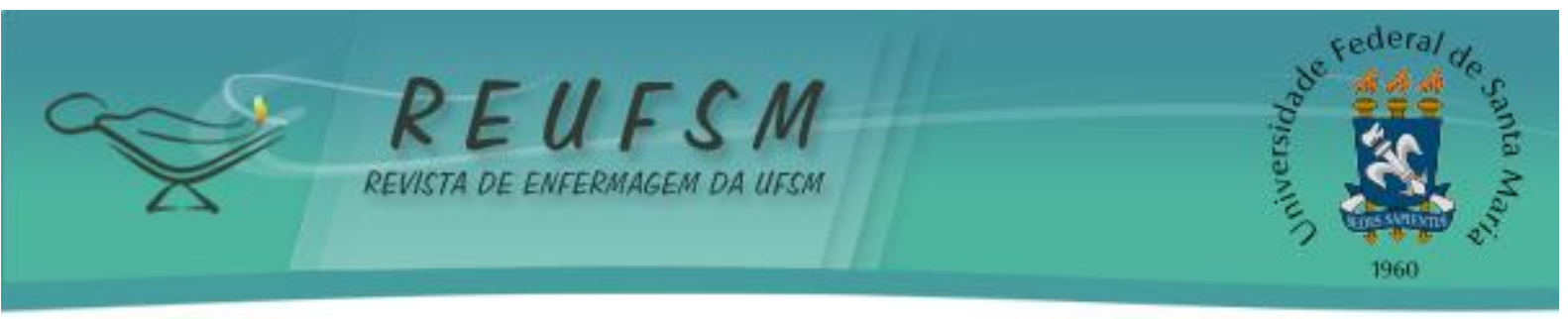

Portanto, destaca-se que a experiência exigiu comprometimento e responsabilidade, bem como possibilitou a satisfação pelas contribuições significativas no processo de formação acadêmica dos alunos monitorados.

\section{REFERÊNCIAS}

1. Conselho Federal de Enfermagem. Código de ética dos profissionais de enfermagem. Rio de Janeiro; 2007 [acesso em 2012 jan 20]. Disponível em: http://site.portalcofen.gov.br/node/4158.

2. Faculdade de Excelência Educacional do Rio Grande do Norte. Histórico de implementação e desenvolvimento da instituição mantenedora e mantida. Natal; 2010.

3. Brasil. Ministério da Educação e do Desporto. Portaria $n^{\circ} 1.721$, de 15 de dezembro de 1994. Estabelece o currículo mínimo do Curso de Graduação em Enfermagem. Diário Oficial da União, Brasília, 1994 dez 16. Seção 1, p. 19.801.

4. Dias MSA, Machado MFAS, Silva RM, Pinheiro AKB. Vivenciando uma proposta emancipatória no ensino de semiologia para a enfermagem. Rev Latinoam Enferm [internet]. 2003 maio-jun [acesso em $2010 \mathrm{dez}$ 12];11(3):364-70. Disponível em: http: / / www.scielo.br/scielo.php?script=sci_arttext\&pid=S0104$11692003000300015 \& l n g=p t . \% 20 d o i: \% 2010.1590 /$ S0104-11692003000300015.

5. Oliveira GF, Araújo CRD. Discentes de semiologia e semiotécnica em enfermagem II: análise da satisfação quanto à disciplina e à escolha da profissão. In: Anais do X Encontro de Iniciação à Docência [internet]; 2007 Dez; João Pessoa. Brasil: UFPB; 2007 [acesso em 2010 nov 22]. Disponível em: http://www.prac.ufpb.br/anais/IXEnex/iniciacao/documentos/anais/6.SAUDE/6CCSDEMCAMT02.pdf.

6. Haag GS, Kolling V, Silva E, Melo SCB, Pinheiro M . Contribuições da monitoria no processo ensino-aprendizagem em enfermagem. Rev Bras Enferm [internet]. 2008 mar-abr [acesso em 2010 dez 10];61(2):215-20. Disponível em: http://www.scielo.br/pdf/reben/v61n2/a11v61n2.pdf.

7. Pelisson EF, Oliveira ES, Hernandes JP, Vrecchi MR, Christophoro R. A monitoria como instrumento de ensino: um relato de experiência. Arq Apadec, 2004 maio;8 (Supl):307-09.

8. Brasil. Ministério da Educação. Lei $n^{\circ} 9.394$, de 20 de dezembro de 1996. Estabelece as diretrizes e bases da educação nacional [internet]. Diário Oficial da União, Brasília, 1996 dez 23 [acesso em 2012 jan 20]. Disponível em: http://www.planalto.gov.br/ccivil_03/leis/L9394.htm\#art92.

9. Fatern. Edital n 004/2009: Programa Institucional de Monitoria 2009.2. Natal; 2009.

10. Vargas JS, Weigelt LD. Bolsista do ensino de gerenciamento em enfermagem: relato de experiência. Rev Enferm UFSM [internet]. 2011 maio-ago [acesso em 2011 set 2];1(2):300-05.

Disponível em: http://cascavel.ufsm.br/revistas/ojs-2.2.2/index.php/reufsm/article/view/2430/1644.

11. Franco GP. Uma experiência acadêmica como aluno-monitor da disciplina de morfologia: histologia e anatomia. Rev Gaúcha Enferm [internet]. 1998 jan [acesso em 2010 dez 15];19(1):66-8. Disponível em:

http://seer.ufrgs.br/RevistaGauchadeEnfermagem/article/viewFile/4176/2214.

12. Gil AC. Como elaborar projetos de pesquisa. $4^{\text {a }}$ ed. São Paulo: Atlas; 2007.

13. Silva EL, Menezes EM. Metodologia da pesquisa e elaboração de dissertação. $3^{a}$ ed. Florianópolis: Laboratório de Ensino a Distância da UFSC; 2001.

14. Rodrigues J, Labronici LM, Mantovani MF, Maftum MA, Taube SAM. Aulas práticas de enfermagem em UTI: construção de conceitos. Cogitare Enferm [internet]. 2006 maio-ago 


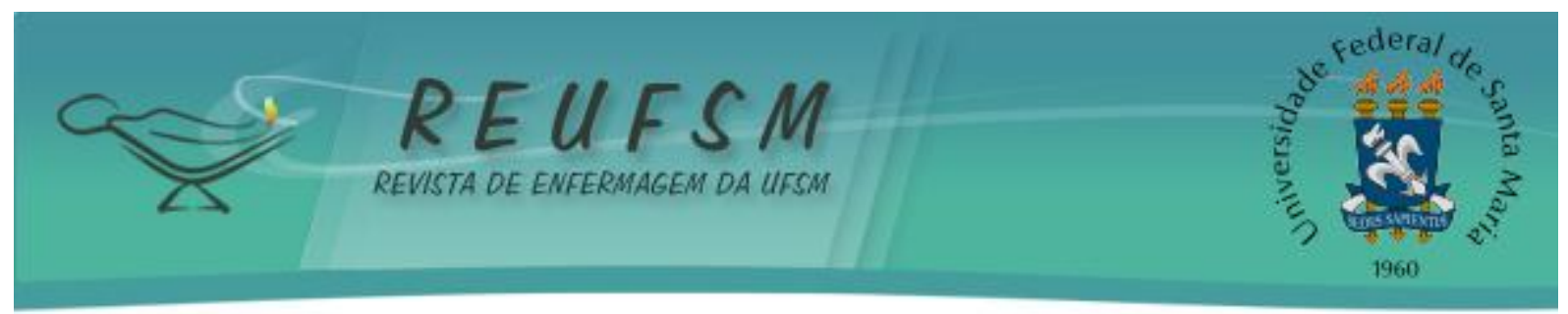

[acesso em 2012 mar 2];11(2):150-55. Disponível em:

http://ojs.c3sl.ufpr.br/ojs2/index.php/cogitare/article/view/6857/4871.

15. Felix CCP, Faro ACM, Dias CRF. Nursing students' perception about the Nursing Laboratory as a teaching strategy. Rev Esc Enferm USP [internet]. 2011 mar [acesso em 2012 mar 2];45(1):24349. Disponível em: http://www.scielo.br/pdf/reeusp/v45n1/en_34.pdf.

16. Moura ECC, Mesquita LFC. Estratégias de ensino-aprendizagem na percepção de graduandos de enfermagem. Rev Bras Enferm [internet]. 2010 set-out [acesso em 2012 mar 2];63(5):793-98. Disponível em: http://www.scielo.br/pdf/reben/v63n5/16.pdf.

17. Gomes CO, Germano RM. Processo ensino-aprendizagem no laboratório de enfermagem: visão de estudantes. Rev Gaúcha Enferm [internet]. 2007 jul-set [acesso em 2012 mar 2];28(3):401-08. Disponível em:

http://seer.ufrgs.br/RevistaGauchadeEnfermagem/article/view/4693/2598.

18. Canalli RTC, Moriya TM, Hayashida M. Acidentes com material biológico entre estudantes de enfermagem. Rev Enferm UERJ [internet]. $2010 \mathrm{abr}$-jun [acesso em 2012 mar 2];18(2):259-64. Disponível em: http://www.facenf.uerj.br/v18n2/v18n2a16.pdf.

19. Natário EG, Santos AAA. Programa de monitores para o ensino superior. Estud Psicol [internet]. 2010 jul-set [acesso em 2012 mar 2];27(3):355-64. Disponível em:

http://www.scielo.br/pdf/estpsi/v27n3/07.pdf.

Data de recebimento: 29/06/2011

Data de aceite: 10/05/2012

Contato com autor responsável: Isaiane da Silva Carvalho

Endereço: Rua Carlos Alexandre, 215, Bairro Frei Damião, Nova Cruz, Rio Grande do Norte, Brasil. CEP: 59215-000

E-mail: isaianekarvalho@hotmail.com 